\title{
Old Europe, new challenges
}

\section{Philippe Durance and Michel Godet}

\author{
Philippe Durance is \\ Associate Researcher and \\ Michel Godet is a Professor, \\ both at the Conservatoire \\ national des arts et métiers \\ (CNAM), Paris, France.
}

\begin{abstract}
Purpose - The paper aims to query the value of strategies implemented, notably in France, and to demonstrate the largely ignored link between demographics and economics.

Design/methodology/approach - The paper achieves its objective by comparing statistics of European Union (EU) members and competitors to reveal that traditional views on economics and social policy may no longer apply.

Findings - The paper finds that the Old Europe stagnated due to political lack of will, but a renewed Europe has begun. The Euro as scapegoat for poor performance is dismissed. Productivity figures show how foreign trade and debt can be efficiently managed. Overall, trade must be encouraged worldwide. Low-wage countries will inevitably compete and cannot ethically be ignored. The subsidy debate heats up as the EU agricultural policy ends and the USA extends Farm Aid. Regardless, EU members must focus on sustainable development. The low birthrate in the Old Europe means social policy should be reformed to encourage families to have children and allow selective immigration to meet labour needs. The implication is that France - Europe in general - must review the EU mission and structure. The French president seems to be headed in this direction. In future research, demographics must be monitored to make social and economic plans for the working lives of our youth and retirement of our seniors.
\end{abstract}

Originality/value - This paper will interest economists, politicians and policy-makers, especially those unaware of the role of demographics in productivity and planning.

Keywords European Union, Economic policy, Social policy, Demographics

Paper type Viewpoint

I t seems like ages ago that the Europe of Maastricht was heading towards enlargement from the Atlantic to the Urals, and preparing for monetary convergence and economic policy cohesion. After the fall of the Berlin Wall, this reunited Europe was supposed to recover all of its former glory, power, and influence. The USA was worried about Fortress Europe and had not yet seen industrialised China conquering the world.

The collective mirage of the new triumphant economy within a global economy vanished at the same time as the single currency was implemented in 12 European countries. Meanwhile Great Britain, always looking farther a field than the continent, kept its Pound Sterling.

Today, Europe's health appears fragile. Jean Monnet's compatriots pulled the emergency brake in the referendum of April 2004 by voting "No" for reasons related to fear of change and years of ambiguity, plus a lack of political courage among European leaders. The European Union actually served as a scapegoat for both the Right and Left in order to liberalise markets and get reforms passed.

The French believed that they could assume the role of European spokesperson under the auspices of a European Union (EU) superpower. The EU, however, remains fractured and politically ineffective. Notwithstanding a permanent seat on the United Nations Security Council, the French, having thrown their entire lot to a floundering European Union, now find 
themselves in a position of diminished political influence. The enlargement of Europe continues but the apparent success is paralyzing the Old Continent more than ever because of the need to reform the Constitution as well as the rules about decisions based on majority rather than unanimity. Certain geo-political analysts would not exclude scenarios in which the EU collapses and member states revert to national currencies. The election of a pro-Union president in France has lead to some progress, at least on the question of a simplified treaty. In sum, Europe has stalled and no serious progress can be made while one of its principal member states is in an election period. In other words, the window of opportunity to move ahead has been narrowed, while Europe's political impotence is increasing along with the number of member states.

However, let us not be pessimistic about the future because, to paraphrase Jean Monnet, Europe exists out of necessity. Issues such as security, immigration policy, negotiation on international trade, and global sustainable development are all good reasons to remain optimistic. Every day Europe is making progress in implementing and regulating. Europe is moving ahead, albeit at its own pace, on previous decisions and directives. The new members from the East are experiencing record growth and integrating quickly into the European economic space, even though they have not benefited from the same aid as Greece and Portugal did during prior enlargements.

These points of convergence should not make us forget the growing divergence among European countries, as observed in growth per capita, working hours, social models, or immigration policies. We need to recognise the fact that rosy promises about market growth and a single currency have not come true. Overall, small member states without a large domestic market have continued to experience greater growth than the large countries and those within the Euro zone. The principal exceptions are Spain and Ireland (see Table I). Otherwise many member states are mired in a soft-growth cycle and a series of budget deficits. The Euro is not to blame, though; it simply served to reveal weaknesses in large countries, like Italy, which can no longer rely on an independent monetary policy prone to frequent devaluations. Similarly, without the Euro (still strong because of Germany's manufacturing surpluses), France would be obliged to devalue its currency and, as in 1983, be more disciplined about managing its expenses and public debt[1].

The times are indeed changing. Germany has recently completed the reunification process and gotten back to work. In fact, Germany will soon break free of the Franco-German couple, now a train without a locomotive, and ask the French, along with other European member states, to pull up their socks. We know that France is the only large, developed country where the majority of the population considers a liberal market economy negatively. This opinion stems from the fact that globalisation is systematically presented as a threat in France. This French exception appears all the more inconsistent given that the world is experiencing unprecedented growth almost everywhere, and is in a state of relative peace, without the spectre of a major world war which would bleed Europe's population dry. Of course, the European population is aging and the old continent must welcome immigrants in order to meet labour shortages that can already be felt. There is still some complementarity in the Franco-German couple to consider, though. Germany remains exemplary in competitiveness; France, in family policy, which enables it to be placed second in EU fertility rates. France manages this despite the regular downgrading of family policies and constant decline in the quality of life for families with children. Yet this fine performance has been tarnished by the failure of a republican integration model that was supposed to be exemplary and universal.

Interestingly, across the Channel, the birthrate soared to a 26-year high, as reported in June 2007. Figures from Britain's Office of National Statistics (ONS) show that women had an average of 1.9 children in 2006, compared with 1.8 children in 2005 and 1.6 in 2001. This statistical increase is due to an influx of immigrants who typically have larger families. Babies born in Britain to mothers of foreign origin accounted for 22 per cent of all births last year, up from 21 per cent the year before (Martin, 2007). 


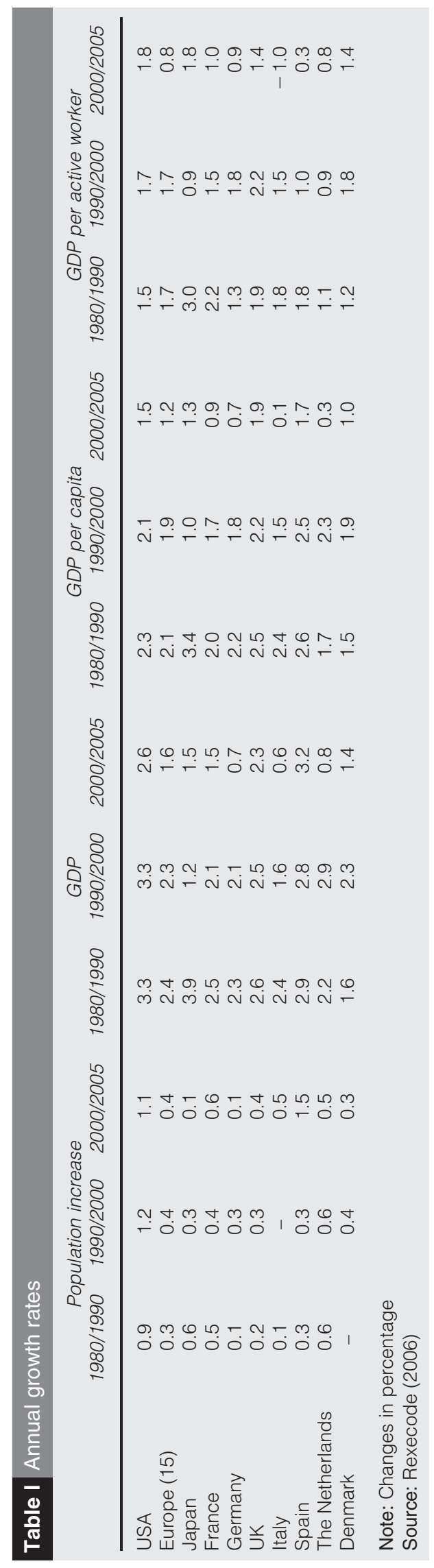

VOL. 9 NO. 62007 foresight $\mid$ PAGE 5 
Not surprisingly, immigration has become a political hot potato in Europe. Recent events in France and Britain, such as the Parisian banlieue riots and the British sentiment that many immigrants are subversive terrorists reveal the divisive nature of immigration in Europe. Yet immigrants generally become productive citizens, especially if the immigration process is structured to promote integration. Until recently, "assimilation" was a dirty word in Britain; however, polls in the UK show that selecting immigrants and requiring them to learn English to ensure "cohesion" may have become acceptable (Marrin, 2007). A revision of immigration policy can be expected in both these EU countries, as the rise of Islamic terrorism and the social stress resulting from ineffective cultural assimilation are far more urgent problems throughout Europe than scientific space missions or a technology race with the USA and East Asia.

Optimism about action should not make us forget to be pragmatic as we consider Europe's problems. Pertinent questions often appear to be impertinent to those involved and some may even be tempted to keep quiet just to keep everyone happy. This is not, however, the case for futurists who must pose the very questions that disturb. In fact, we want to raise a few disturbing topics such as reforming the CAP, liberalising Europe to trade and globalisation; industry's role in economic competitiveness, and the consequences of an aging population on economic growth.

\section{Open Europe does not mean discount Europe}

Liberalisation of international trade has led to unprecedented growth around the world. Since 1947, average customs tariffs have fallen by approximately 90 per cent among industrialised countries. Meanwhile, trade has increased 20-fold; world production, tenfold. The next step is to attack non-tariff barriers and protectionist practices of countries such as the USA.

An open Europe must not mean a discounted Europe, though. In fact the EU must use all its influence on the World Trade Organisation (WTO) to organise free trade and oppose the "law of the strongest". All of Europe should agree on the principle of reciprocity in terms of open borders. All this should be done, of course, without ever giving in to the temptation of protectionism.

Competition from countries with cheap labour certainly makes the headlines. Overall, however, the EU has balanced trade with the rest of the world. In fact, trade represents approximately one-quarter of European production (the same for France), while two-thirds of its imports and exports are destined for Europe itself. It would be dangerous then to regulate trade and production according to employment figures because countries share an advantage in trade, even if that advantage is unevenly distributed. Thanks to trade, countries grow mutually richer whereas if they close their borders to trade, they grow mutually poorer and cease making progress.

Everyone benefits from the internationalisation of trade. In fact, even if jobs are lost in some sectors, wealth is increased overall. Accusing newly industrialised nations is no longer acceptable because OECD and Economic Analysis Council (CAE) studies have shown that overall foreign trade represents a positive net balance in employment. In terms of ethics, one cannot ask weaker countries to accept anti-competition laws when favourable and reject them when inconvenient. One cannot refuse to import what low-wage countries produce more competitively since low labour costs constitute these countries' principal comparative advantage. Encouraging less developed countries to trade remains the most effective tool for improving their social situation.

Greater specialisation is profitable in industrialised countries because it leverages comparative advantage. A glance at the French and German cases make this point clear. Industrial imports represent approximately 40 per cent of domestic consumption in both France and Germany. However, the share of such imports coming from low-wage countries (low-value goods which require a lot of unskilled labour) in that category is only 11 per cent in France versus 24 per cent in Germany. In other words, German industry is better in terms of sourcing and exploiting cheaper supplies. This explains how the Germans were able to 
return to a trade surplus shortly after reunification, and how they remain both more competitive and more specialised than the French.

Globalisation does not necessarily mean diminished standards of living. However, for the less-developed countries to catch up, economic and social changes will be necessary in the more advanced countries, and these changes will prove all the more painful because they will likely come as a surprise.

\section{Revise the CAP without forgetting "food as weapon"}

On the basis of the Berlin agreements and the Luxemburg compromise in 2003, the CAP is scheduled to end in 2013. In the years leading up to 2013, market liberalisation, and decreases in subsidies of all kinds, including export assistance and direct aid to farmers, will take place gradually. It is true that we were subsidising agricultural products. These sorts of subsidies distort agricultural markets, encourage inefficiency, and create wasteful surpluses. A full 80 per cent of agricultural subsidies were allocated to 20 per cent of farmers, most of whom were using intensive methods of cultivation, which ravishes the environment and requires greater inputs of scarce water.

This decoupling of subsidies with production - total or progressive, depending on the country - means that the 80 per cent of farmers who received 20 per cent of the funds will continue to farm only if they can make more money by producing crops rather than by doing nothing. This is actually a programmed revolution in European agricultural policy in which we hope to buy the silence of farmers, ever fewer in number, by continuing to subsidise them without their producing anything or rather with the justified environmental restrictions. This "Last of the Mohicans" scenario has not been rejected by farmers because they may actually come out ahead. It is similar to paying for past crops and since there are fewer farmers, each one makes the same, perhaps more, even if farm aid decreases overall. The result of this ineffective policy will likely be a partial decentralisation of the agricultural policy throughout Europe.

The CAP represents over 40 per cent of community expenses for 2 per cent of the active population. CAP opponents never miss a chance to brandish these figures and call for the dismantling of the common policy in the name of other European priorities made necessary by enlargement or simply through modernity, which encourages us to develop through research, training, infrastructure and social policy. Actually, agriculture is the only field in which community policy replaced national policies, and where European and national public aid, which is devoted to agriculture in Europe, does not surpass its proportion in the active population.

The CAP has been a great success in Europe but must be completely revised if only because new Eastern members are now integrating into the Union. Their entry implies the conversion and modernisation of an active labour force similar to that of France in the 1950s. Logical farming, with its emphasis on "traceability", and respect for the environment, is only the first step toward sustainable development. We all know that the subsidies granted in rich countries have led to artificial prices worldwide. Indeed these prices are unrelated to real production costs and, in the end, too low to cover production and importation from less-developed countries. For instance, in Europe and the USA, where 70 per cent of the overall cotton production is concentrated, the subsidy per kilo has surpassed the selling price. In these conditions, the more competitive African cotton cannot fetch a fair price hence its production and export cannot develop normally. The same logic applies to cereal, sugar and other staples.

Given the clout of the USA, the world price of agricultural products is often a dumping price designed to move American surpluses. If the CAP is to be revised according to the principals of sustainable development, it will be important to do so without US pressure. Of course, not all EU members are equally invested in agriculture. France represents 20 per cent of the net added value of European agriculture; Italy, 19 per cent; Spain, 18 per cent and the others follow far behind, e.g. Germany, 10 per cent; Greece, 7 per cent and the UK, 6.5 per cent. Europe must not let down its guard, though. Agricultural aid is slightly lower in 
volume in the USA, but higher per farmer ( $\$ 20,000$ in the USA vs $\$ 14,000$ in the EU). According to the Farm Bill, American agricultural assistance should increase by 70 per cent in ten years. In other words, now is not the time to dismantle our system while the Americans are reinforcing theirs. The "food weapon" should not be available in the USA alone; Europe should have it, too.

The lessons learned from our adventures in agricultural policy are the following: liberalisation of markets and globalisation have their limits. Certain strategic sectors, particularly those related to national identity and heritage, such as agriculture in France, merit protection. Failing to do so would severely upset social order and solidarity.

\section{Business as usual?}

In today's global economy, Europe can stand proud. Indeed, the Europe of 25 is by far the top commercial power in the world. If we exclude intra-trading, which represents on average two-thirds of the exports of each member state, Europe represents 19 per cent of the world's exports versus 14 per cent for the USA and approximately 9 per cent for Japan and China. External trade transactions, which have doubled since 2002, despite energy costs, remain more or less balanced with a deficit of approximately 60 billion Euros and a surplus of over 70 billion Euros if we consider the Eurozone, led by Germany. Such is not the case in the USA with its abysmal foreign trade deficit of 500 billion Euros. China and Japan recorded trade surpluses of 27 billion Euros and 78 billion Euros respectively in 2004 (most recent available data).

This positive performance is due essentially to a reunified industrial Germany whose 2004 surplus was approximately 160 billion Euros (versus 30 billion in 1993 and 60 billion in 2000). Ireland serves as the notable exception with a positive balance of 35 billion Euros vis-à-vis the rest of the non-European world; Italy is balanced, too, whereas all the other European countries have posted a structural deficit, e.g. France: 13 billion Euros; Spain: 56 billion Euros; UK: 94 billion Euros. How can we explain these differences among countries within the Union?

One explanation remains worth examining here: countries that perform best internationally are those that manage to maintain a solid industrial foundation. While the weight of industry and energy in the added value of the Europe of 25 hovers around 20 per cent on average, it is 25 per cent for Germany; 28 per cent for Ireland and 21 per cent for Italy versus only 18 per cent for the UK and Spain, and 16 per cent for France. This flood of figures reveals a great deal about the future.

Germany weighs in at double France in terms of exports within the Union versus exports to the rest of the world (27 per cent vs 13 per cent). Germany's principal strength lies in the surplus for "machinery and equipment" - 155 billion Euros versus only 11 billion Euros in France. Chemical products follow at 31 billion euros in Germany versus 10 billion in France. "Other manufactured goods" represents 29 billion euros in Germany against a deficit of 19 billion euros in France. This last item underscores the fact that industrial specialisation is the best line of defence against an invasion of imports from emerging countries with low labour costs.

If European manufacturers wish to compete internationally, they must specialise with innovative products and services with a high quotient of added value. There are neither condemned sectors nor commercial fatalities due to companies themselves. There are, however, poor managers and entrepreneurs who no longer question their production methods in an ever-changing world where innovation is necessary. Companies that remain content selling what they produce are indeed condemned because in order to conquer a market, one must produce what actually sells; i.e. goods and services that meet real or latent needs. Innovative entrepreneurs are the true motors of growth. However innovation should always be plural, i.e. technical for processes and products, but also commercial, financial, and social.

\section{No sustainable growth without children}

Reports on technology, innovation and competitiveness fill libraries and line drawers. In these documents, workers are often treated merely as human capital. In terms of training, the employer is considered correctly as an investment and a long-term growth factor. 
Demographics are generally treated only in terms of aging from the top down (more seniors) with the ensuing problems. However, little is presented on the consequences of aging from the bottom up (fewer young people) and the impact on growth and Europe's place in the world.

Economists "refuse to see" the link between economic growth and demographics thus they do not even verify it (Sauvy, 1980). Comparisons of growth rates in Europe and the USA usually use technology to explain long-term differences. One wonders though if there is not also a demographic multiplier effect (Godet and Durance, 2006) (see Box 1.)

European countries are like orchards full of trees. After 40 fruitful years, the grove reached maturity without anyone having planted new seeds. If we are to invest and consume, we must be optimistic about the future and prepare for it. These are characteristics that, unfortunately, decline with age. In economics and demographics, the same dynamic applies: a zest for life may be expressed in terms of an economic initiative or a nursery full of children. The family spirit is closely related to the corporate spirit.

European leaders are well aware of aging from the top down. They know that health and retirement plans will require some painful measures. For instance, we need to ensure that funds will be available to support those aged 80 and greater, a demographic that will double by the year 2035! We may push back these dates, but overall the younger generation, still working but fewer in number, will have to pay for the older generation's care.

Regional development factors are endogenous and depend upon the economic dynamics of the local active population. The more people there are, and the more entrepreneurial they behave, the healthier the region. In short, the problems of economic development are internal, and the impact of globalisation on our economies must seriously be put into perspective.

In order to compensate for a demographic deficit, Europe must open up the borders to considerable but selective immigration. Integration will need to be legislated through public and family policies that are more flexible in terms of integration. In fact, integration will go better if there is a mix, especially in the schools. Hence the need to encourage people to have children in the old European countries, like France and Germany, where polls indicate

\section{Box 1. Beware the technology mirage of the knowledge society}

Europe is infatuated with the concept of the knowledge society or economy, even setting itself the goal of becoming a world leader in this category. An aging Old World is reassured about its future, imagined as full of grey-haired sages with youthful spirits and innovative minds.

Meanwhile the capacity of companies to "learn how to learn" has become a key factor in measuring competitiveness. However, many firms have developed contrary practices, as seen in their urgent and reactive behavior that prevails over any projects or foresight efforts. The memory of ideas is being ignored, even destroyed. Getting rid of workers over the age of 55; i.e. holders of the celebrated human capital that is supposedly valued so much, bears eloquent witness to this attitude. If we are moving towards the knowledge economy, we really must respect knowledge rather than mistreat it.

Knowledge is indeed the driving force of innovation, while technology remains important but not always essential. We should stop considering R\&D expenses as the principal indicator of hope for the future. The efficiency of expenditure counts more than the amount spent. International comparative studies show that the most successful companies within a sector are those making an average R\&D effort. In others words, they are taking action while spending less[2].

Given this finding, do we really need to launch massive research projects in high-tech sectors and develop advanced higher education, as so many official reports claim? Unlike Germany, France already over-invests in "research-intensive" sectors[3] and underfunds research in medium- or even low-technology sectors and in small-to-medium-size businesses. In comparison with Germany, France has almost double the number of graduates from institutions of higher education but one-fifth the number of apprentices. Also, France's foreign balance in equipment is three times weaker! We can do the math! Again, in comparison with Germany, France lacks major small-to-medium-size industries because of the very high cost of capital and problems related to estate transfers[4]. So far this message has barely resonated in Paris and in Brussels as the Lisbon Strategy was primarily concerned with investment in information technology. 
that one in two women would like another child but cannot because of the problems inherent in balancing family and career. Similarly recent British statistics indicate that slightly higher birthrates do not reflect such a rosy picture. Experts see some women over age 35 who delayed having children now giving birth, but many in the middle-income bracket decide not to have children because of the spiralling costs of living (Martin, 2007).

Overall, aging from the top down is actually good news for Europeans who are living longer and in better health. There is bad news only when there is no next generation to take up the baton. What must be avoided is aging from the bottom of the pyramid. Otherwise what good is "saving the whales", if there are no more children around to see them?

\section{Notes}

1. Thanks to the Euro, France latched onto the German industrial train. A double-edged sword in that if France still were using the franc against the mark, the country would surely have been obliged to implement reforms on hours worked (the French work three weeks fewer than the Spanish and five weeks fewer than the British) and to accept competitive devaluations. France's bilateral deficit with Germany (10 billion Euros) is comparable to the deficit with China, but we do not hear about it. The time has come for France to adopt the virtuous Germanic industrial model.

2. Through an analysis of the top 1,000 international companies, the American firm of strategic consultants, Booz Allen Hamilton, actually showed that according to R\&D budgets, there was no direct link between R\&D expenses and corporate success. This holds whether success is measured in terms of business growth, profitability or return on investment for shareholders (Strategy + Business, 2005).

3. A total of 40 per cent of public expenditures on research are concentrated in the nuclear, space and military sectors and a few large corporations benefit initially from this funding.

4. In France, there are only 2,000 industrial companies with fewer than 250 salaried employees. These companies account for 65 per cent of the added value in the sector and assure 80 per cent of the exports. Some 25 per cent of the added value returns to the 20,000 companies with between 50 and 250 employees. Only 1 per cent annually of "creators"; i.e. 2,000 people, start a business in the industrial sector.

\section{References}

Godet, M. and Durance, P. (2006), "Europe: grey hair, low growth”, Foresight, Vol. 8 No. 2, pp. 10-29.

Marrin, M. (2007), "Should we limit immigrants to Europeans?", The Sunday Times, 17 June.

Martin, N. (2007a), "Migrants push birth rate to highest in decades", Telegraph.co.uk, 9 June.

Sauvy, A. (1980), "Démographie et refus de voir", L'enjeu démographique, Éditions de l'Association pour la Recherche et I'Information Démographique (APRD), Paris.

Strategy + Business (2005), "Money isn't everything. Lavish R\&D budgets don't guarantee performance", No. 41, Winter.

\section{About the authors}

Philippe Durance is Associate Researcher at the Conservatoire national des arts et métiers (CNAM) in Paris. Philippe Durance is the corresponding author and can be contacted at: ph.durance@wanadoo.fr

Michel Godet is a Professor at the Conservatoire national des arts et métiers (CNAM, www. cnam.fr/lipsor/) in Paris and member of the Economic Analysis Council (CAE) advising the Prime Minister of France. He is the author of Creating Futures, Scenario Building as a Strategic Management Tool (Economica, 2006).

To purchase reprints of this article please e-mail: reprints@emeraldinsight.com Or visit our web site for further details: www.emeraldinsight.com/reprints 